\title{
Originals
}

\section{Plasma Beta-thromboglobulin in Diabetes Mellitus}

\author{
D. Q. Borsey, J. Dawes ${ }^{1}$, D. M. Fraser, C. V. Prowse ${ }^{2}$, R. A. Elton ${ }^{3}$, and B. F. Clarke \\ Diabetic and Dietetic Department, Royal Infirmary of Edinburgh, ${ }^{1}$ M. R. C. Immunoassay Team, ${ }^{2}$ South-East Scotland Regional Blood \\ Transfusion Service, and ${ }^{3}$ Medical Computing and Statistics Unit, University of Edinburgh, Edinburgh, Scotland
}

\begin{abstract}
Summary. Plasma beta-thromboglobulin was measured, using the Edinburgh radioimmunoassay technique and anticoagulant mixture (containing prostaglandin E1) in 61 normal subjects, 67 diabetics with and 54 diabetics without microangiopathic complications. Plasma beta-thromboglobulin was significantly higher in the diabetic patients $(p<0.01)$ but there was no significant difference between the two diabetic groups. Twenty-six normal subjects, 27 diabetics with and 39 diabetics without complications were studied further by measuring beta-thromboglobulin in four different ways using two different radioimmunoassay techniques and two anticoagulant mixtures (with and without prostaglandin E1). The Edinburgh assay gave a value 1.97 times that obtained with the Amersham assay, and the Edinburgh anticoagulant a value 0.78 times that with the Amersham anticoagulant. Beta-thromboglobulin concentration in the meniscus layer was approximately twice that in the middle layer. The lower betathromboglobulin values obtained with the Edinburgh anticoagulant may result from a different sampling technique or from prevention of in vitro beta-thromboglobulin release, after venepuncture, by prostaglandin E1. Abnormal platelet behaviour in diabetes was confirmed although its role in the pathogenesis of microangiopathic complications remains unclear.
\end{abstract}

Key words: Plasma beta-thromboglobulin, radioimmunoassay technique, prostaglandin E1 anticoagulant, plasma layer, diabetic microangiopathy, diabetes mellitus.

Despite intensive research the precise pathogenesis of the specific microangiopathic complications of diabetes mellitus remains obscure [1]. However, it seems clear that multiple factors are involved and, amongst these, abnormalities of platelet function may be of considerable importance [1-3].

In 1975 a platelet specific protein released during platelet aggregation was isolated and named betathromboglobulin ( $\beta \mathrm{TG}$ ) [4]. A highly sensitive radioimmunoassay has been developed for its measurement in biological fluids [5] and a commercial radioimmunoassay kit (Thromboglobulin RIA kit, Radiochemical Centre, Amersham) is now available. Although no biological function has yet been ascribed to $\beta \mathrm{TG}$ it has been shown to be elevated in certain thromboembolic states [6-9]. Recent studies of the relationship between plasma $\beta$ TG levels and microangiopathic complications of diabetes have produced inconsistent results [10-12].

Two technical differences in obtaining the plasma sample were noted between the above studies. The anticoagulant mixture used in Edinburgh [10] included prostaglanding E1 (a potent platelet antiaggregating agent) whereas the subsequent Sheffield [11] and Oxford [12] studies used the Amersham kit from which prostaglandin was omitted. This led to the suggestion that plasma $\beta$ TG may be normal in most diabetic patients, the recorded increases [11, 12] being the result of in vitro $\beta$ TG release after venesection, and that a potential platelet hypersensitivity may exist in diabetes which is blocked in the presence of prostaglandin E1 [13]. The second variation concerns the fraction of plasma taken for assay. After centrifugation of the blood samples users of the Amersham kit are recommended to remove the top $0.5 \mathrm{ml}$ of the plasma (meniscus layer) for assay whereas with the Edinburgh technique the same volume is removed from the middle layer. It has been found that platelets may be trapped at the meniscus and result in an elevated $\beta$ TG concentration in this layer [14].

We have studied three groups of subjects (nondiabetic controls and diabetics with and without mi- 
Table 1. Details of subjects in whom plasma $\beta$-thromboglobulin was measured using the Edinburgh anticoagulant and Edinburgh assay

\begin{tabular}{|c|c|c|c|c|c|c|c|}
\hline \multirow[t]{2}{*}{ Subjects } & \multirow[t]{2}{*}{$\begin{array}{l}\text { Age } \\
\text { Mean } \pm S D\end{array}$} & \multirow[t]{2}{*}{$\begin{array}{l}\text { Sex } \\
\% \text { Male }\end{array}$} & \multirow{2}{*}{$\begin{array}{l}\text { Duration of } \\
\text { diabetes } \\
\text { Median and range } \\
\text { (Years) }\end{array}$} & \multicolumn{3}{|c|}{ Treatment } & \multirow{2}{*}{$\begin{array}{l}\text { Plasma } \beta \text {-throm- } \\
\text { boglobulin } \\
\text { Median and } \\
\text { range }(\mathrm{ng} / \mathrm{ml})\end{array}$} \\
\hline & & & & Insulin & Oral agents & Diet alone & \\
\hline $\begin{array}{l}\text { Normal subjects } \\
(\mathrm{n}=61)\end{array}$ & $34 \pm 14$ & 60.7 & - & - & - & - & $\begin{array}{l}32 \\
(15-120)\end{array}$ \\
\hline $\begin{array}{l}\text { Total diabetics } \\
(\mathrm{n}=121)\end{array}$ & $55 \pm 15$ & 50.4 & $\begin{array}{l}14 \\
(0-45)\end{array}$ & 71 & 39 & 11 & $\begin{array}{l}44^{\mathrm{a}} \\
(11-923)\end{array}$ \\
\hline $\begin{array}{l}\text { Diabetics without } \\
\text { complications } \\
(\mathrm{n}=54)\end{array}$ & $56 \pm 15$ & 53.7 & $\begin{array}{l}8 \\
(0-37)\end{array}$ & 20 & 23 & 11 & $\begin{array}{l}47 \\
(11-923)\end{array}$ \\
\hline $\begin{array}{l}\text { Diabetics with } \\
\text { complications } \\
(n=67)\end{array}$ & $54 \pm 15$ & 47.8 & $\begin{array}{l}19 \\
(4-45)\end{array}$ & 51 & 16 & 0 & $\begin{array}{l}42^{\mathrm{b}} \\
(13-488)\end{array}$ \\
\hline
\end{tabular}

${ }^{\mathrm{a}} \mathrm{p}<0.01$ when compared with controls

${ }^{b} \mathrm{p}$ not significant when compared with uncomplicated diabetics

Wilcoxon Rank Sum test

croangiopathic complications) and measured $\beta$ TG concentrations, on simultaneous blood samples, in four ways by using the different anticoagulant and assay techniques available. Furthermore, we have assessed the contribution of the meniscus layer to variation between assays.

\section{Patients and Methods}

Three groups of subjects were studied; [1] 61 normal subjects; [2] 54 diabetic patients without retinopathy and clinical or biochemical evidence of nephropathy; [3] 67 diabetic patients with significant retinopathy of whom 16 had evidence of nephropathy. Significant retinopathy was defined as greater than 4 microaneurysms per fundus. Nineteen patients had background retinopathy of mild or moderate severity and 48 patients either very extensive background retinopathy or proliferative retinopathy. The age, sex, duration of diabetes and treatment of the patients are shown in Table 1. None of the subjects studied were receiving medications known to interfere with platelet function.

Venous samples $(2.7 \mathrm{ml})$ were withdrawn without stasis into polypropylene syringes, and transferred immediately to a siliconised glass tube containing the platelet release inhibitors edetic acid (EDTA), prostaglandin E1 and theophylline (Edinburgh anticoagulant). The tubes were centrifuged at $1900 \mathrm{~g}$ for one hour at $0^{\circ} \mathrm{C}$ as previously described [5]. The middle third of the platelet poor plasma was removed for radioimmunoassay of $\beta \mathrm{TG}$ as described by Bolton et al. (Edinburgh assay) [15]. In all cases simultaneous venous plasma glucose concentrations were estimated and in 46 diabetics total glycosylated haemoglobin $\left(\mathrm{HbA}_{1}\right)$ was also measured [16].

Ninety-two patients (26 normal subjects, 39 diabetics without and 27 diabetics with complications) were studied further by measuring $\beta$ TG levels on simultaneous venous blood samples by four different techniques; [1] Edinburgh anticoagulant and Edinburgh assay, [2] Edinburgh anticoagulant and Amersham radioimmunoassay kit, [3] Amersham anticoagulant (EDTA and theophylline but no prostaglandin E1 in a plastic tube) and Edinburgh assay, [4] Amersham anticoagulant and Amersham assay.
In addition, blood samples were taken into Amersham tubes from 24 controls and 24 diabetic patients. After centrifugation of the sample, $0.1 \mathrm{ml}$ of the meniscus layer, $0.5 \mathrm{ml}$ of the middle layer and $0.1 \mathrm{ml}$ of the deep liquid layer were taken for $\beta$ TG assay by the Edinburgh method.

\section{Statistical Methods}

The measured variables did not have a normal distribution and the data is therefore expressed as median and range. The significance of difference between groups was assessed by the Wilcoxon Rank Sum test.

An analysis of variance was carried out on the logarithms of the four values measured by different methods on each of the 92 samples. Logarithms were used because examination of the data measured by each pair of methods suggested that differences in measurement values between methods were likely to be proportional rather than independent of the values themselves. The differences in overall mean value for the two anticoagulants and two assays in this analysis were converted (by taking antilogs) to estimates of the multiplicative factors by which the two methods differ. Confidence limits were placed on these estimates. A similar analysis of variance was carried out on the measurement of $\beta \mathrm{TG}$ concentrations in the meniscus, middle and deep layers of the samples.

\section{Results}

The median and range of $\beta$ TG concentrations in the three groups studied using the Edinburgh anticoagulant and the Edinburgh assay is shown in Table 1 and the individual values are depicted in Figure 1. The plasma $\beta$ TG concentrations were significantly higher in the diabetic patients than in the normal subjects $(\mathrm{p}<0.01)$. However, there was no significant difference between the $\beta$ TG levels of diabetics with and without complications. There was no correlation between the $\beta$ TG concentrations and the age, sex, 
duration of diabetes, treatment, simultaneous plasma glucose or $\mathrm{HbA}_{1}$ levels.

The median and range of $\beta$ TG levels obtained by the 4 different measurement techniques is shown in Table 2. There was a significant difference in the $\beta \mathrm{TG}$ levels between non-diabetic and diabetic groups by all 4 methods but again no significant difference between diabetics with and without complications.

The results of the analysis of variance on the 4 measured values in each of the 92 samples is shown in Table 3. There was no significant interaction between assays, anticoagulant and patient type (diabetic or normal). This indicates that the data is consistent with a model in which the assay and anticoagulant used have independent multiplicative effects on the expected measurement values, these effects also being independent of patient type. The variance ratio for samples within patient types shows that a highly significant difference exists in $\beta$ TG values between different patients of the same type as well as between diabetics and normal subjects.

It was estimated that, on average, the Edinburgh assay will give a value that is 1.97 times that for the Amersham assay (95\% confidence limits, 1.85 and 2.09) and that use of the Edinburgh anticoagulant will give a value that is 0.78 times that when the Amersham anticoagulant is used $(0.73$ and 0.83$)$. The fit to the data of these estimates is exemplified by the broken line in Figure 2 which shows the relationship expected when the factor of 1.97 (a constant difference of 0.294 on the logarithmic scale) is applied to the data using the Edinburgh anticoagulant.

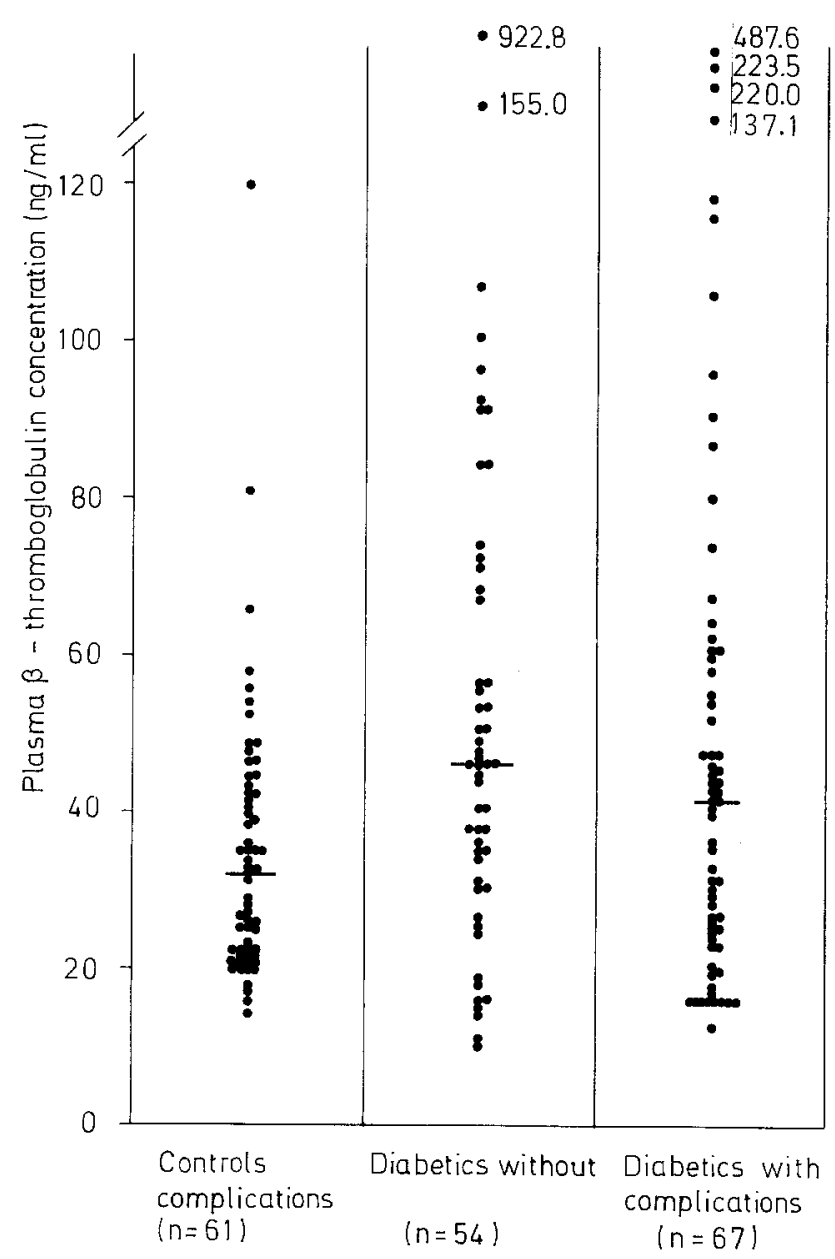

Fig. 1. Plasma $\beta$-thromboglobulin concentrations (Edinburgh anticoagulant and Edinburgh assay) in diabetic patients, with and without complications, and normal subjects. The horizontal bars represent median values

Table 2. Plasma $\beta$-thromboglobulin concentrations in diabetic patients and normal subjects measured by 4 different techniques (median and range $\mathrm{ng} / \mathrm{ml}$ )

\begin{tabular}{|c|c|c|c|c|c|c|c|c|}
\hline \multirow{3}{*}{$\begin{array}{l}\text { Subjects } \\
\begin{array}{l}\text { Normal subjects } \\
(\mathrm{n}=26)\end{array}\end{array}$} & \multicolumn{4}{|c|}{ Edinburgh assay } & \multicolumn{4}{|c|}{ Amersham assay } \\
\hline & \multicolumn{2}{|c|}{ Edinburgh anticoagulant } & \multicolumn{2}{|c|}{ Amersham anticoagulant } & \multicolumn{2}{|c|}{ Edinburgh anticoagulant } & \multicolumn{2}{|c|}{ Amersham anticoagulant } \\
\hline & $\begin{array}{l}35 \\
(18-200)\end{array}$ & \multirow{2}{*}{$\mathrm{p}<0.001$} & $\begin{array}{l}43 \\
(20-195)\end{array}$ & \multirow[b]{2}{*}{$\mathrm{p}<0.001$} & $\begin{array}{l}22 \\
(<10-85)\end{array}$ & & $\begin{array}{l}30 \\
(10-88)\end{array}$ & \multirow[b]{2}{*}{$\mathrm{p}<0.001$} \\
\hline $\begin{array}{l}\text { Total diabetics } \\
(n=66)\end{array}$ & $\begin{array}{l}55 \\
(16-923)\end{array}$ & & $\begin{array}{l}81 \\
(25-1114)\end{array}$ & & $\begin{array}{l}32 \\
(10-218)\end{array}$ & $\mathrm{p}<0.005$ & $\begin{array}{l}41 \\
(10-218)\end{array}$ & \\
\hline $\begin{array}{l}\text { Diabetics without } \\
\text { complications } \\
(\mathrm{n}=39) \\
\text { Diabetics with } \\
\text { complications } \\
(\mathrm{n}=27)\end{array}$ & $\begin{array}{l}51 \\
(16-923) \\
61 \\
(32-488)\end{array}$ & NS & $\begin{array}{l}88 \\
(25-1114) \\
78 \\
(31-480)\end{array}$ & NS & $\begin{array}{l}32 \\
(10-218) \\
36 \\
(10-114)\end{array}$ & NS & $\begin{array}{l}40 \\
(10-218) \\
42 \\
(17-141)\end{array}$ & NS \\
\hline
\end{tabular}

Wilcoxon Rank Sum test 


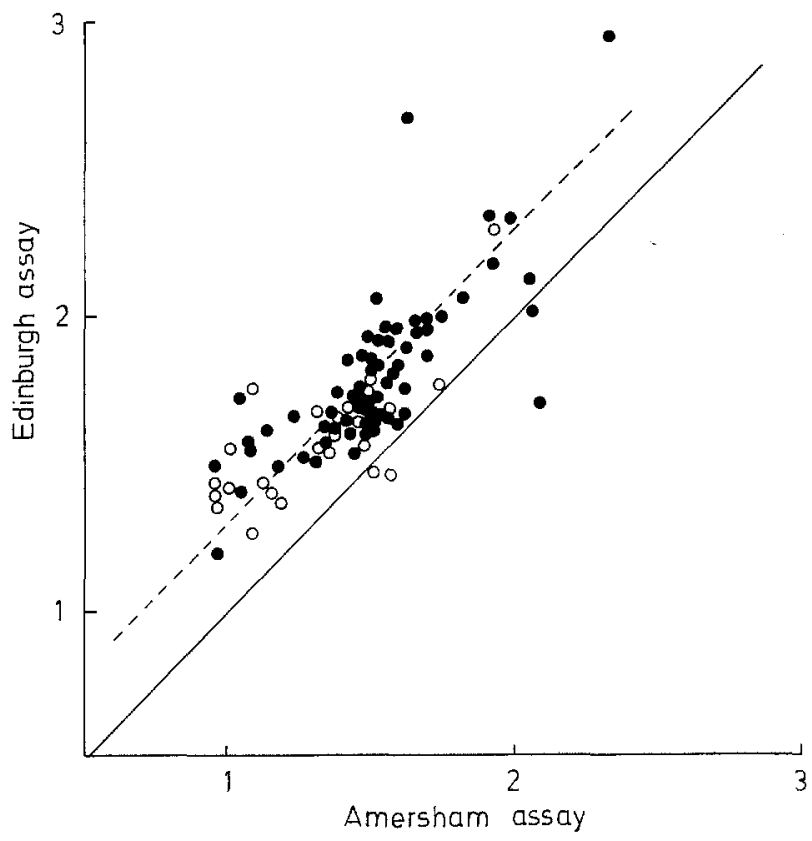

Fig. 2. Plot of plasma $\beta$-thromboglobulin values obtained using Edinburgh anticoagulant with the two different assays (logarithmic scale) for non-diabetic $(O)$ and diabetic $(0)$ patients. The solid line shows identity between the two assays and the broken line the mean relationship estimated from the analysis of variance

Table 3. Analysis of variance of the logarithms of $\beta$-thromboglobulin as measured by four methods on samples from 66 diabetic patients and 26 normal subjects

\begin{tabular}{lrrrr}
\hline Source of variation & $\begin{array}{l}\text { Sum of } \\
\text { squares }\end{array}$ & $\begin{array}{l}\text { Degrees of } \\
\text { freedom }\end{array}$ & $\begin{array}{l}\text { Mean } \\
\text { variance }\end{array}$ & $\begin{array}{l}\text { Variance } \\
\text { ratio }\end{array}$ \\
\hline $\begin{array}{l}\text { Type of patient } \\
\text { Samples within }\end{array}$ & 3.637 & 1 & 3.637 & $192.53^{\mathrm{a}}$ \\
types & 20.599 & 90 & 0.229 & $12.10^{\mathrm{a}}$ \\
Assay & 7.954 & 1 & 7.954 & $420.66^{\mathrm{a}}$ \\
Tube & 1.120 & 1 & 1.120 & $59.21^{\mathrm{a}}$ \\
Type $\times$ assay & 0.039 & 1 & 0.039 & 2.08 \\
Type $\times$ tube & 0.007 & 1 & 0.007 & 0.38 \\
Assay $\times$ tube & 0.014 & 1 & 0.014 & 0.74 \\
Type $\times$ assay $\times$ & & & & \\
tube & 0.012 & 1 & 0.012 & 0.63 \\
Residual & 5.105 & 270 & 0.019 & \\
\hline Total & 38.487 & 367 & & \\
\hline
\end{tabular}

${ }^{\mathrm{a}} \mathrm{p}<0.001$
Differences between the logarithms of the $\beta \mathrm{TG}$ concentrations in the meniscus, middle and deep layers of plasma samples from 24 normal controls and 24 diabetic patients are shown in Table 4 . The meniscus layer yielded on average a $\beta$ TG value approximately twice that obtained from the middle layer, and the diabetics were significantly more variable than the normals in the proportional difference between these two layers. The mean log difference between the middle and deep layers, however, was not significant.

\section{Discussion}

The finding of elevated plasma $\beta$ TG concentrations in diabetics supports the reports from Sheffield [11] and Oxford [12] although it contrasts with a previous study in Edinburgh [10] which showed no significant difference in $\beta$ TG levels betwen normal subjects and diabetic patients with complications. This latter study is subject to statistical criticism. The difference in age between the diabetic patients ( $55 \pm 15$ years) and the normal subjects ( $34 \pm 14$ years) does not account for our findings since Dewar et al. [17] found no significant increase in plasma $\beta$ TG with age throughout the range we have studied. No significant difference was found in $\beta$ TG concentrations between diabetics with and without microangiopathic complications. This differs from two previous reports [11, 12], although the Oxford workers found that there was no correlation between the degree of $\beta \mathrm{TG}$ elevation and the severity of complications (retinopathy, neuropathy and large vessel disease).

By measuring $\beta \mathrm{TG}$ by four different techniques we have shown that the anticoagulant and the assay used have independent effects on the expected values. The lower $\beta$ TG values obtained using the Edinburgh anticoagulant may result from prevention of in vitro $\beta$ TG release, after venepuncture, by the presence of prostaglandin E1. However, as the above factors are independent of patient type this must occur in both diabetics and normal subjects, rather than in diabetics alone as previously suggested [13].

Table 4. Analysis of differences of the logarithms of $\beta$-thromboglobulin between plasma layers from 24 diabetic patients and 24 normal subjects

\begin{tabular}{lccccc}
\hline Plasma layers & $\begin{array}{l}\text { Normal subjects } \\
\text { Mean (SD) }\end{array}$ & $\begin{array}{l}\text { Diabetics } \\
\text { Mean (SD) }\end{array}$ & F & t & $\begin{array}{l}\text { Estimate and 95\% } \\
\text { confidence interval for } \\
\text { proportional difference }\end{array}$ \\
\hline Meniscus - middle & $0.29(0.15)$ & $0.39(0.23)$ & $2.29^{\mathrm{a}}$ & 1.73 & $2.19(1.68,2.85)$ \\
Middle - deep & $0.09(0.18)$ & $0.07(0.18)$ & 1.07 & 0.47 & $1.20(0.95,1.53)$ \\
Deep - meniscus & $-0.38(0.19)$ & $-0.32(0.26)$ & 1.93 & 0.94 & $0.44(0.33,0.60)$ \\
\hline
\end{tabular}

${ }^{\mathrm{a}} \mathrm{p}<0.05$ 
Perhaps more important is the effect of sampling from the meniscus layer since this not only increases the $\beta$ TG concentration measured, but may also introduce an extraneous source of variation between normal and patient samples.

The lack of a significant difference in $\beta$ TG values between the two diabetic groups suggests that raised levels in diabetics are not secondary to the development of microangiopathic complications. This is supported by the finding of elevated $\beta$ TG levels in newly diagnosed insulin independent diabetics which fell once plasma glucose control was achieved [11]. This suggests that metabolic disturbance may be responsible for the elevation of $\beta$ TG in diabetics either by directly affecting function or endothelial interactions of platelets. Although we found no correlation between $\beta \mathrm{TG}$ and simultaneous $\mathrm{HbA}_{1}$ and plasma glucose, fluctuations in other metabolites such as lipids may result in elevated $\beta$ TG levels. Abnormally high plasma cholesterol and triglyceride concentrations have been reported in two uncomplicated diabetic patients with elevated $\beta$ TG levels (126 and $146 \mathrm{ng} /$ ml) [12]. Other possible sources of raised $\beta \mathrm{TG}$ concentrations in diabetics include an increased platelet turnover, a primary platelet defect or vascular endothelial damage.

Our study adds weight to the already considerable evidence in favour of abnormal platelet behaviour in diabetes. However, definitive evidence for the importance of abnormal platelet function in the pathogenesis of diabetic microangiopathy has yet to be provided.

Acknowledgements. We wish to thank Dr. J. D. Cash, National Medical Director of the Scottish National Blood Transfusion Service and Dr. D. S. Pepper, South-East Scotland Regional Blood Transfusion Service, Edinburgh, for their expert advice.

\section{References}

1. McMillan E D, Ditzel J (1976) Proceedings of a Conference on Diabetic Microangiopathy. Diabetes 25 [Suppl 2]: 805-930

2. Mustard J F, Packham MA (1977) Platelets and diabetes mellitus. N Engl J Med 297: 1345-1347

3. Waitzman MB, Colley A M, Nardelli-Olkowska K (1977) Metabolic approaches to studies on diabetic microangiopathy. Diabetes 26: 510-519
4. Moore S, Pepper DS, Cash JD (1975) The isolation and characterisation of a platelet specific $\beta$-globulin ( $\beta$-thromboglobulin) and the detection of anti-urokinase and anti-plasmin released from thrombin-aggregated washed human platelets. Biochim Biophys Acta 379: 360-369

5. Ludlam C A, Cash JD (1976) Studies on the liberation of $\beta$ thromboglobulin from human platelets in vitro. Br J Haematol 33: $239-249$

6. Ludlam C A, Bolton A E, Moore S, Cash J D (1975) New rapid method for diagnosis of deep venous thrombosis. Lancet II: $259-260$

7. Denham MJ, Fisher M, James G, Hassan M (1977) $\beta$-thromboglobulin in clinical conditions. Lancet I: 1154

8. Redman CWG, Allington MJ, Bolton FG, Stirrat GM (1977) Plasma $\beta$-thromboglobulin in pre-eclampsia. Lancet II: 248

9. Ludlam C A, Moore S, Bolton A E, Pepper D S, Cash J D (1975) The release of a human platelet specific protein measured by radioimmunoassay. Thromb Res 6: 543-548

10. Campbell I W, Dawes J, Fraser D M, Pepper D S, Clarke B F, Duncan LJ P, Cash JD (1977) Plasma $\beta$-thromboglobulin in diabetes mellitus. Diabetes 26: 1175-1177

11. Preston F E, Ward J D, Marcola B H, Porter N R, Timperley W R, O'Malley B C (1978) Elevated $\beta$-thromboglobulin levels and circulating platelet aggregates in diabetic microangiopathy. Lancet I: $238-240$

12. Burrows A W, Chavin S I, Hockaday T D R (1978) Plasmathromboglobulin concentrations in diabetes mellitus. Lancet I: 235-237

13. Editorial (1978) Platelets, beta-thromboglobulin and diabetes mellitus. Lancet I: 250-251

14. Rasi V (1979) $\beta$-thromboglobulin in plasma; false high values caused by platelet enrichment of the top layer of plasma during centrifugation. Thromb Res 15: 543-552

15. Bolton A E, Ludlam CA, Moore S, Pepper D S, Cash J D (1976) Three approaches to the radioimmonosassay of human $\beta$-thromboglobulin. Br J Haematol 33: 233-238

16. Kynoch PAM, Lehman H (1977) Rapid estimation (21/2 hours) of glycosylated haemoglobin for routine purposes. Lancet II: 16

17. Dewar H A, Marshall T, Weightman D, Prakash V, Boon P J (1979) Beta-thromboglobulin in antecubital vein blood: the influence of age, sex and blood group. Thromb Haemostas 42: 1159-1163

18. Ferguson J C, Mackay N, Philip J A D, Sumner D J (1975) Determination of platelet and fibrinogen half-life with $\left(75_{\mathrm{SE}}\right)$ selenomethionine: studies in normal and in diabetic subjects. Clin Sci Mol Med 49: 115-120

Received: June 25, 1979, and in revised form: November 23, 1979

Dr. D. Q. Borsey

Diabetic and Dietetic Department

Royal Infirmary of Edinburgh

Edinburgh EH3 9YW

Scotland 